\title{
Expert opinion on the cough hypersensitivity syndrome in respiratory medicine
}

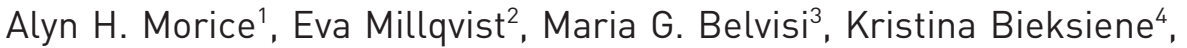 \\ Surinder S. Birring ${ }^{5}$, Kian Fan Chung ${ }^{6}$, Roberto W. Dal Negro ${ }^{7}$, \\ Peter Dicpinigaitis ${ }^{8}$, Ahmad Kantar ${ }^{9}$, Lorcan P. McGarvey ${ }^{10}$, \\ Adalberto Pacheco ${ }^{11}$, Raimundas Sakalauskas ${ }^{4}$ and Jaclyn A. Smith ${ }^{12}$
}

\begin{abstract}
Affiliations: 'Centre for Cardiovascular and Metabolic Research, Respiratory Medicine, Hull York Medical School, University of Hull, Cottingham, UK. ${ }^{2}$ Dept of Internal Medicine/Respiratory Medicine and Allergology, University of Gothenburg, Gothenburg, Sweden. ${ }^{3}$ Respiratory Pharmacology Group. Pharmacology and Toxicology Section, National Heart and Lung Institute, Imperial College London, London, UK. ${ }^{4}$ Dept of Pulmonology and Immunology, Lithuanian University of Health Science, Kaunas, Lithuania. ${ }^{5}$ Division of Asthma, Allergy and Lung Biology, King's College London, London, UK. ${ }^{6}$ National Heart and Lung Institute, Imperial College London and Biomedical Research Unit, Royal Brompton and Harefield NHS Trust, London, UK. ${ }^{7}$ Centro Nazionale Studi di Farmacoeconomia e Farmacoepidemiologua Respiratoria CESFAR, Verona, Italy. ${ }^{8}$ Einstein Division/Montefiore Medical Center, Albert Einstein College of Medicine, New York, NY, USA. ${ }^{9}$ Paediatric Cough and Asthma Centre, Istituti Ospedalieri Bergamaschi, Bergamo, Italy. ${ }^{10}$ Centre for Infection and Immunity, Queen's University Belfast, Belfast, UK. ${ }^{11}$ Chronic Cough Unit, Pneumology Service, Hospital Ramón y Cajal, Madrid, Spain. ${ }^{12}$ Centre for Respiratory and Allergy, University of Manchester, University Hospital of South Manchester, Manchester, UK.
\end{abstract}

Correspondence: Alyn H. Morice, Centre for Cardiovascular and Metabolic Research, Respiratory Medicine, Hull York Medical School, University of Hull, Castle Hill Hospital, Castle Road, Cottingham, East Yorkshire, HU16 5JQ, UK. E-mail: a.h.moricedhull.ac.uk

ABSTRACT In 2011, a European Respiratory Society Task Force embarked on a process to determine the position and clinical relevance of the cough hypersensitivity syndrome, a disorder characterised by troublesome coughing often triggered by low levels of thermal, mechanical or chemical exposure, in the management of patients with chronic cough. A 21-component questionnaire was developed by an iterative process supported by a literature review. 44 key opinion leaders in respiratory medicine were selected and interviewed as to their opinions.

There was a high degree of unanimity in the responses obtained, with all opinion leaders supporting the concept of cough hypersensitivity as a clinically useful paradigm. The classic stratification of cough into asthmatic, rhinitic and reflux-related phenotypes was supported. Significant disparity of opinion was seen in the response to two questions concerning the therapy of chronic cough. First, the role of acid suppression in reflux cough was questioned. Secondly, the opinion leaders were split as to whether a trial of oral steroids was indicated to establish a diagnosis of eosinophilic cough.

The cough hypersensitivity syndrome was clearly endorsed by the opinion leaders as a valid and useful concept. They considered that support of patients with chronic cough was inadequate and the Task Force recommends that further work is urgently required in this neglected area.

@ERSpublications

Cough hypersensitivity syndrome was clearly endorsed by opinion leaders as a valid and useful concept http://ow.ly/zxk83

For editorial comments see page 1103.

Received: Dec 152013 | Accepted after revision: May 082014 | First published online: Aug 192014

Conflict of interest: Disclosures can be found alongside the online version of this article at erj.ersjournals.com

Copyright @ERS 2014 


\section{Introduction}

Chronic cough is a common presentation to both primary and secondary care. The management of these patients is often problematic, with relatively few therapeutic options. Many suffer long-term illness with a marked adverse effect on quality of life and major medical and socio-economic consequences.

Our understanding of chronic cough has traditionally revolved around three diagnostic categories: a form of asthma, rhinitis, and reflux disease. However, few patients fit into these conventional categories with ease. Indeed, in many patients the aetiology of their cough remains obscure, despite extensive and repeated clinical assessments, and the terms "chronic", "idiopathic" or "refractory" cough have been coined in response to this diagnostic uncertainty.

More recently, a unifying hypothesis, that chronic cough arises from a hypersensitivity of airway sensory nerves, has been proposed. Various internal and external provoking agents are suggested to lead to this afferent neuronal hypersensitivity. In May 2011, the Scientific Committee of the European Respiratory Society (ERS) commissioned a Task Force to examine the attitudes to, and evidence behind, our understanding of the aetiology and treatment of chronic cough. The aim of the Task Force was to establish international opinion on the clinical relevance of cough hypersensitivity. Here we report the major output of the Task Force, a survey of opinion leaders in respiratory medicine using a questionnaire developed through a consensus process. A comprehensive review of the literature by the Task Force members informed a commentary on the survey findings.

\section{Methods}

At the 2011 ERS Congress, the Task Force convened and members presented a comprehensive review based on PubMed literature search. The indexed terms "cough" and "chronic cough" were used in addition to individually assigned topics. The quality of individual papers was not formally assessed, but this review was used as the basis for constructing a set of key thematic questions concerning the aetiology, diagnosis and treatment of chronic cough.

In March 2012, the Task Force met and undertook a consensus process to refine the questionnaire. Using a round table iterative procedure, individual topics were ranked for priority and questions were constructed. Each individual question was approved by unanimous vote of the Task Force committee. A total of 21 questions were approved. It was agreed that respondents were to be asked to provide a single response out of five possible answers graded from "agree strongly" to "disagree strongly". A "long list" of key opinion leaders in respiratory medicine from a wide geographical range and covering a comprehensive spectrum of relevant sub-specialities was drawn up. The selection of opinion leaders was by national or international reputation as demonstrated by publication record, and required unanimous agreement. Respondents were asked to undertake the questionnaire using an individualised methodology, each Task Force member acting as interlocutor. If conducted by face-to-face interview, prompting of responses was not permitted; clarification of the meaning of questions, either orally or in writing, was allowed to ensure standardisation.

\section{Results}

A total of 44 opinion leaders from 14 countries participated in the survey. The responses from individuals $(n=7)$ who failed to fully complete the questionnaire were included with missing data left blank. The country of residence and primary speciality of the respondents are listed in table 1 . Individual questions and Task Force responses are detailed in the following sections.

\section{Cough hypersensitivity syndrome \\ Question 1}

Cough hypersensitivity syndrome (CHS) is a clinical syndrome characterised by troublesome coughing often triggered by low levels of thermal, mechanical or chemical exposure

$\begin{array}{llr}\text { A+ } & \text { Agree strongly } & 14 \\ \text { A } & \text { Agree with minor reservations } & 25 \\ \text { A- } & \text { Agree with major reservations } & 4 \\ \text { D- } & \text { Disagree with major reservations } & 0 \\ \text { D } & \text { Disagree with minor reservations } & 0 \\ \text { D+ } & \text { Disagree strongly } & 1\end{array}$

A majority of the interviewees (39 out of 44) agreed strongly or agreed with minor reservations, indicating the legitimacy of CHS as a useful diagnostic concept. Only one of the interviewees disagreed strongly, but the degree of positive response indicates a substantial consensus supporting the CHS as an established and accepted clinical entity. 
TABLE 1 Country of residence and primary speciality of 44 survey respondents

Respondents $n$

$\begin{array}{lr}\text { Country } & \\ \text { Australia } & 2 \\ \text { Belgium } & 2 \\ \text { Canada } & 1 \\ \text { China } & 1 \\ \text { Denmark } & 1 \\ \text { Greece } & 2 \\ \text { Ireland } & 1 \\ \text { Italy } & 1 \\ \text { Lithuania } & 6 \\ \text { Spain } & 1 \\ \text { Sweden } & 3 \\ \text { The Netherlands } & 7 \\ \text { UK } & 9 \\ \text { USA } & 7 \\ \text { Primary speciality } & \\ \text { Ear, nose and throat } & 6 \\ \text { Gastroenterology } & 2 \\ \text { General practice } & 4 \\ \text { Paediatrics } & 5 \\ \text { Respiratory medicine } & 27\end{array}$

The CHS is a relatively new paradigm that accounts for unexplained cough and includes apparently diverse groups of chronic cough patients, both those with symptoms that may indicate accepted aetiologies such as a reflux disease and those with a general hypersensitivity towards, for example, environmental irritants [1-4]. The diagnosis of CHS comprises not only patients suffering from chronic idiopathic cough, but also encompasses patients with other conditions who demonstrate a heightened response to inhaled coughprovoking stimuli such as citric acid or capsaicin $[1,2,5]$. The syndrome focuses on the chronic cough patient and provides an "umbrella" for different conditions where cough is a major component. Other symptoms of the CHS include a persistent tickling or irritating sensation in the chest or throat, hoarse voice, dysphonia and the perception of laryngeal obstruction that may be provoked by low-dose exposure to environmental irritants like tobacco smoke and perfumed products [6]. The pathophysiology behind the hypersensitivity is debated; it has been suggested that this may result from a neuropathic condition $[7,8]$, although direct evidence of nerve damage is lacking. Increased neuronal excitability is supported by an upregulation of transient receptor potential (TRP) nociceptors in airway epithelium [9] and nerves of chronic cough patients [10].

Question 2

CHS may mimic or coexist with other pulmonary or extrapulmonary disease

$\begin{array}{llr}\text { A+ } & \text { Agree strongly } & 23 \\ \text { A } & \text { Agree with minor reservations } & 13 \\ \text { A- } & \text { Agree with major reservations } & 6 \\ \text { D- } & \text { Disagree with major reservations } & 1 \\ \text { D } & \text { Disagree with minor reservations } & 1 \\ \text { D+ } & \text { Disagree strongly } & 0\end{array}$

There was a consensus among opinion leaders that the CHS forms a major component of many other respiratory conditions. Multiple prospective studies [11,12] have previously asserted that the majority of cases of chronic cough in adults are associated with one or more of three aetiological groups: rhinosinusitis or upper airway cough syndrome; eosinophilic airway inflammation; and gastro-oesophageal reflux. This view is enshrined in guidelines $[13,14]$. However, only a small minority of individuals with these common conditions actually complain of a chronic cough. Conversely, while in most individuals an acute cough due to the common cold resolves within days, in a small percentage this heralds the onset of a relentless, intractable chronic cough. Indeed, many patients with chronic cough will recall the onset of their illness as temporally related to an episode of viral upper respiratory tract infection.

CHS has been proposed as the explanation for the occurrence of a chronic, refractory cough as a consequence of illness that, in the majority of other individuals, would have induced no more than a 
transient, self-limited cough. This perspective implies the superimposition of a cough-triggering illness in an individual predisposed to CHS or with baseline or pre-existing hypersensitivity state. Whether CHS in isolation can cause chronic cough remains a subject of debate [15].

The overlap between CHS and other conditions, such as asthma, chronic obstructive pulmonary disease (COPD), bronchiectasis and idiopathic pulmonary fibrosis, where a coexistent prominent cough may be present, remains to be elucidated. The majority of our opinion leaders considered that an overlap was likely, either agreeing strongly or with minor reservations. It will require the development of specific pharmacological antagonists of the CHS to definitively apportion the degree to which symptoms in these conditions are due to CHS or to the underlying pathological process.

\section{Mechanisms of cough hypersensitivity \\ Question 3}

Cough sensitivity is distinct from methacholine bronchial responsiveness and reflects afferent perception of a wide range of stimuli

$\begin{array}{llr}\text { A+ } & \text { Agree strongly } & 21 \\ \text { A } & \text { Agree with minor reservations } & 15 \\ \text { A- } & \text { Agree with major reservations } & 8 \\ \text { D- } & \text { Disagree with major reservations } & 0 \\ \text { D } & \text { Disagree with minor reservations } & 0 \\ \text { D+ } & \text { Disagree strongly } & 0\end{array}$

All the opinion leaders agreed, although with some reservations, that cough reflex sensitivity is distinct from methacholine bronchial responsiveness. Methacholine acts directly on muscarinic receptors on airway smooth muscle, leading to its contraction [16]. Thus, bronchial hyperresponsiveness, such as occurs in asthma, appears to be an increase in activity of the end organ. In contrast, cough sensitivity is an afferent response to chemical or mechanical stimuli activating specific sensory neurones leading through the reflex arc to the expulsive effort of a cough. Patients with chronic cough report a wide range of triggers. Their symptoms may suggest hypersensitivity to external tussive stimuli, such as smoke and pungent vapours, or to physiological triggers such as talking. Most patients with refractory chronic cough report abnormal sensations in the pharynx or larynx, such as a tickle or an itch, possibly suggesting a paraesthesia [17]. Animal studies demonstrate that the vagus nerve carries airway afferent fibres to the nucleus tractus solitarius in the brain stem [18]. Although the receptors mediating spontaneous cough in humans have not been unequivocally identified, nociceptors such as TRPV1 and TRPA1 ion channels and rapidly adapting nerve fibres have been implicated $[19,20]$. Which component (or components) of the afferent arm of the cough reflex is responsible for the hypersensitivity state remains to be elucidated.

\section{Cough and neuronal mechanisms \\ Question 4}

Airway inflammation is directly responsible for activation of sensory nerves in cough

$\begin{array}{llr}\text { A+ } & \text { Agree strongly } & 9 \\ \text { A } & \text { Agree with minor reservations } & 9 \\ \text { A- } & \text { Agree with major reservations } & 17 \\ \text { D- } & \text { Disagree with major reservations } & 5 \\ \text { D } & \text { Disagree with minor reservations } & 4 \\ \text { D+ } & \text { Disagree strongly } & 0\end{array}$

The role of airway inflammation in the activation of sensory nerves was not clearly established in the mind of the opinion leaders, with the majority agreeing with a major reservation. Cough is initiated by action potential discharge in terminals of primary airway vagal afferent nerves. When considering the sensory neurobiology of the airways, there are two main pathways. Capsaicin and endogenous inflammatory agents (e.g. bradykinin and prostaglandin E2) evoke action potential discharge mainly in nonmyelinated, jugular vagal C-fibres [21]. However, the myelinated, nodose vagal afferent A $\delta$ fibres, which conduct action potentials at $3-5 \mathrm{~m} \cdot \mathrm{s}^{-1}$, can also be activated to evoke cough and are exquisitely sensitive to punctate mechanical stimulation and osmotic solutions and not to inflammatory stimuli $[18,22]$. Thus, cough may be provoked by direct mechanical stimulation in conditions such as inhaled foreign body or anatomical disruption of the airway by a tumour. The equivocal response of our opinion leaders may reflect an understanding of this dual mechanism, one liable to potentiation by inflammation and one responding to mechanical stimulation and therefore less likely to be influenced by humoral factors. 


\section{Question 5}

Upregulation of neuronal (central and peripheral) mechanism is a key feature of CHS

$\begin{array}{llr}\text { A+ } & \text { Agree strongly } & 10 \\ \text { A } & \text { Agree with minor reservations } & 21 \\ \text { A- } & \text { Agree with major reservations } & 11 \\ \text { D- } & \text { Disagree with major reservations } & 0 \\ \text { D } & \text { Disagree with minor reservations } & 1 \\ \text { D+ } & \text { Disagree strongly } & 1\end{array}$

The upregulation of the neuronal mechanisms is clearly recognised as being a major component of the underlying aetiology of cough hypersensitivity. Data from animal and human studies would suggest that the local environment around airway afferents and/or the phenotype of these nerves may change in the airways of patients with CHS. How this occurs, in which population of afferents and at which neuronal target is unclear. A currently favoured explanation is that inflammatory mediators could "sensitise" Cfibre afferent nerve endings (peripheral or central) leading to an increase in the electrical excitability of afferent nerves, thus reducing the threshold for activation. In some patients, cough hypersensitivity persists after an inflammatory response or viral/bacterial infection has subsided, and it has been suggested that this may be due to a change in the gene expression profile in the airway afferent nerves leading to a phenotype change. This phenomenon has been reported in the somatosensory system and can lead to phenotype changes [23]. Thus, low-threshold mechanoreceptors can take on chemosensitive or nociceptor phenotypes by expressing substance $\mathrm{P}$, typically limited to the $\mathrm{C}$-fibre afferents. This phenomenon has also been reported to occur in airway vagal $A \delta$ fibres in an asthma model in sensitised guinea pigs following allergen challenge [24]. In these studies, neurotrophic factors produced as a consequence of allergic airway inflammation induced the expression of TRPV1 in tracheal A $\delta$ fibres that do not express TRPV 1 under "normal" circumstances [25].

The cough reflex

Question 6

Cough reflex hypersensitivity accounts for most symptoms in patients with chronic cough

$\begin{array}{llr}\text { A+ } & \text { Agree strongly } & 4 \\ \text { A } & \text { Agree with minor reservations } & 16 \\ \text { A- } & \text { Agree with major reservations } & 14 \\ \text { D- } & \text { Disagree with major reservations } & 6 \\ \text { D } & \text { Disagree with minor reservations } & 4 \\ \text { D+ } & \text { Disagree strongly } & 0\end{array}$

The majority of opinion leaders agreed that hypersensitivity of the cough reflex accounted for symptoms in patients with chronic cough. Interestingly, reservations about this statement were more frequent than for question one, describing the clinical syndrome. This would suggest some uncertainty about the mechanisms that underlie chronic cough and the relative role of airway inflammation as a provoking stimulus of the symptom complex.

While it is well established that coughing in health is a protective reflex, the mechanisms underlying cough in disease are not well understood. Patients presenting to specialist cough clinics are often found to have components of their illness suggestive of asthma, nasal disease or gastro-oesophageal reflux, yet the vast majority of individuals with these conditions do not present with severe coughing. This observation would imply that an additional pathology is operating in such patients, and the most intuitive hypothesis would be that the heightened neuronal excitability of CHS accounts for the excessive coughing.

Current methodologies for measuring cough reflex sensitivity, such as responses to capsaicin, poorly discriminate patients with chronic cough from healthy controls; although the average sensitivity to these irritants is increased, there is substantial overlap in the data distributions [26]. Therefore, unlike tests of bronchial hyperresponsiveness such as methacholine challenge, inhalation of these agents is not diagnostically useful [27]. These observations may explain some of the uncertainty about the role of neuronal hypersensitivity in the minds of opinion leaders. However, alternative challenge protocols and end-points may ultimately resolve these issues [28]. 
Question 7

A single cough challenge estimation is of no value in clinical practice because of too much overlap with a wide normal range

$\begin{array}{llr}\text { A }+ & \text { Agree strongly } & 12 \\ \text { A } & \text { Agree with minor reservations } & 14 \\ \text { A- } & \text { Agree with major reservations } & 11 \\ \text { D- } & \text { Disagree with major reservations } & 4 \\ \text { D } & \text { Disagree with minor reservations } & 1 \\ \text { D+ } & \text { Disagree strongly } & 0\end{array}$

None of the opinion leaders felt that estimation of the cough sensitivity using inhalational cough challenge should be used in routine clinical practice. Inhalation cough challenge testing with either capsaicin or citric acid has established itself as an important clinical research tool, allowing the measurement of cough reflex sensitivity in a safe and highly reproducible manner [27, 29, 30]. Studies involving serial cough challenges can demonstrate the effect of a pathological condition or therapeutic intervention on cough reflex sensitivity; single cough challenge assessments can be used in epidemiological studies comparing populations. However, a single cough challenge study performed in an individual patient provides limited information, because of the great variability in baseline cough reflex sensitivity within the population $[26,27,29,30]$. Indeed, "normal" or "abnormal" cough challenge values cannot be defined with methods used today, since they do not appear to directly evaluate afferent sensitivity. Thus, isolated measurements of the cough reflex cannot independently distinguish a healthy subject from a patient with pathological cough, be it due to asthma [26, 31, 32], COPD [26, 33, 34], gastro-oesophageal reflux disease [31] or other conditions. Some investigators, however, do report clinically useful information derived from single cough challenge assessments performed in specific patient populations [6].

Cough and eosinophils

Question 8

A steroid-responsive cough is characterised by eosinophilic inflammation of the airways

$\begin{array}{llr}\text { A+ } & \text { Agree strongly } & 11 \\ \text { A } & \text { Agree with minor reservations } & 14 \\ \text { A- } & \text { Agree with major reservations } & 14 \\ \text { D- } & \text { Disagree with major reservations } & 2 \\ \text { D } & \text { Disagree with minor reservations } & 2 \\ \text { D+ } & \text { Disagree strongly } & 1\end{array}$

A chronic cough responding to a trial of a steroid therapy, either parenterally or by inhalation, was thought to indicate the presence of eosinophilic inflammation by the majority of the opinion leaders. The reverse of this statement, that in a patient with chronic cough, assessment of airway inflammation can be used to identify patients who are likely to respond to inhaled corticosteroids, has been demonstrated [35]. At the outset of the management of the patient with a chronic cough, a clear distinction must be made between cough due to corticosteroid-responsive eosinophilic airway diseases and corticosteroid-resistant noneosinophilic cough, since management differs markedly. Unless this distinction is made, steroid therapy may be continued without evidence of response, with consequent risk of adverse events. A short-term diagnostic trial of oral corticosteroids has been recommended [36] on the basis that, in some patients, inhaled steroid therapy appears to be inadequate and high-dose prednisolone is required to control cough [37]. Other evidence, such as the effect of a tyrosine kinase inhibitor controlling not only eosinophilia but also cough in hypereosinophilic syndrome characterised by aberrant tyrosine kinase activity, is consistent with this view [37]. However, a recent study demonstrating the ability of monoclonal anti-interleukin-5 therapy to significantly reduce the number of asthmatic exacerbations without affecting a simple subjective assessment of cough [38] raises the question of a direct role for eosinophils in the aetiology of asthmarelated cough. Additional work, particularly investigation of the role of the mast cell, is required.

Eosinophilic airway inflammation may coexist with gastro-oesophageal reflux and should be taken into consideration when interpreting exhaled nitric oxide measurements [39]. In this phenotype of eosinophilic airway inflammation with reflux, a trial of corticosteroids can be supported for persistent symptoms and to minimise the risk of progression to bronchoconstriction with subsequent development of fixed airflow obstruction [40]. 
Question 9

Eosinophilic cough includes classic asthma, cough variant asthma and nonasthmatic eosinophilic bronchitis

$\begin{array}{llr}\text { A+ } & \text { Agree strongly } & 15 \\ \text { A } & \text { Agree with minor reservations } & 21 \\ \text { A- } & \text { Agree with major reservations } & 3 \\ \text { D- } & \text { Disagree with major reservations } & 1 \\ \text { D } & \text { Disagree with minor reservations } & 2 \\ \text { D+ } & \text { Disagree strongly } & 2\end{array}$

That inhaled and oral corticosteroids can be effective in controlling cough in some individuals has been suggested to indicate a diagnosis of an "eosinophilic cough" syndrome. A number of discrete phenotypes are recognised and these distinct syndromes were recognised by our opinion leaders. Cough as the sole respiratory symptom in patients with normal spirometry but evidence of bronchial hyperresponsiveness and who report improvement with bronchodilators or corticosteroids receive the diagnosis of cough variant asthma [41]. Cough may also be the most troublesome symptom for patients with the more typical features of asthma, including airflow obstruction and coexistent wheeze and dyspnoea [42]. This is sometimes termed "classic" or "cough predominant" asthma [43]. The recognition that some cough patients have no airway dysfunction (specifically no bronchial hyperresponsiveness) but have airway eosinophila and a steroid-responsive cough led to the term "nonasthmatic eosinophilic bronchitis". This latter phenotype accounts for between $10 \%$ and $15 \%$ of cases of chronic cough [44, 45] and, since anti-inflammatory treatment with inhaled corticosteroids or leukotriene antagonists is associated with improvement of the cough and a reduction in airway eosinophils $[46,47]$, is an important differential diagnosis in the patient with chronic cough.

\section{Question 10}

A diagnosis of eosinophilic cough may be supported by induced sputum, exhaled nitric oxide and blood eosinophilia

$\begin{array}{llr}\text { A+ } & \text { Agree strongly } & 11 \\ \text { A } & \text { Agree with minor reservations } & 19 \\ \text { A- } & \text { Agree with major reservations } & 9 \\ \text { D- } & \text { Disagree with major reservations } & 4 \\ \text { D } & \text { Disagree with minor reservations } & 1 \\ \text { D+ } & \text { Disagree strongly } & 0\end{array}$

The opinion leaders supported the suggestion that objective evidence of eosinophilic inflammation should be sought. The assessment of airway inflammation by quantification of induced sputum eosinophils and exhaled nitric oxide measurement offers low sensitivity but high specificity and is predictive of response to corticosteroid therapy $[48,49]$. The correlation between exhaled nitric oxide fraction (FeNO) and sputum eosinophilia is good in corticosteroid-naive patients, but this relationship is weaker once patients are treated [50]. Larger studies investigating the diagnostic accuracy and clinical usefulness of FeNO tests compared with induced sputum and bronchoprovocation tests are needed to determine which test is optimal for the investigation of eosinophilic cough.

Eosinophilia is a feature of many different lung diseases. In some conditions, eosinophils are increased in the blood but not in the lung tissue; in other diseases, there may be significant eosinophilia in the lung tissue but not in the peripheral blood [51].

The correlation between peripheral blood eosinophilia and cough is unclear. In exacerbations of COPD, an eosinophil count of $>2 \%$ is associated with good response to corticosteroids [38]. Whether this simple diagnostic can be extrapolated in eosinophilic cough remains to be elucidated.

\section{Question 11}

A therapeutic trial of oral steroids is indicated to confirm the diagnosis of eosinophilic cough

$\begin{array}{llr}\text { A+ } & \text { Agree strongly } & 4 \\ \text { A } & \text { Agree with minor reservations } & 18 \\ \text { A- } & \text { Agree with major reservations } & 8 \\ \text { D- } & \text { Disagree with major reservations } & 6 \\ \text { D } & \text { Disagree with minor reservations } & 4 \\ \text { D+ } & \text { Disagree strongly } & 3\end{array}$


Opinion was more evenly divided as to whether a therapeutic trial of oral corticosteroids should be undertaken in patients with chronic cough. In COPD, such trials are no longer recommended because of the difficulty in defining response and the variability of individual patient response with time. The patient with cough variant asthma or eosinophilic bronchitis presents a diagnostic challenge in the clinic. As already discussed, investigations such as sputum eosinophil count and exhaled nitric oxide may be used as screening tools and may have led some of the respondents to disagree; however, such tests are not routinely available in all clinics. Inhaled corticosteroid trials may be unsuccessful because of compliance, technique, duration and induction of cough by inhalation [52]. Possible side-effects may be off-putting. A therapeutic trial with oral steroids is therefore recommended in the ERS consensus statement [14] and may be appropriate where circumstances dictate. The absence of objective assessment of response, outside specialist clinics, presents further problems, since it relies on subjective measures, and oral corticosteroid therapy may simply improve mood in a condition with a marked adverse effect on quality of life. If an oral corticosteroid trial is undertaken then careful assessment of response should be documented and, if response is absent or minimal, therapy discontinued.

\section{Cough and reflux}

Question 12

Proton pump inhibitors (PPIs) are an effective treatment for reflux-associated CHS

$\begin{array}{llr}\text { A+ } & \text { Agree strongly } & 4 \\ \text { A } & \text { Agree with minor reservations } & 13 \\ \text { A- } & \text { Agree with major reservations } & 9 \\ \text { D- } & \text { Disagree with major reservations } & 7 \\ \text { D } & \text { Disagree with minor reservations } & 7 \\ \text { D+ } & \text { Disagree strongly } & 3\end{array}$

There was a wide distribution of responses from the opinion leaders as to the effectiveness of PPIs in chronic cough due to reflux. Gastro-oesophageal reflux has long been described as a cause of chronic cough. The reported prevalence of this condition in patients with cough varies from occasional to very frequent, depending on the population studied and the diagnostic criteria used [53]. A particular problem is whether gastro-oesophageal reflux is diagnosed solely on the criterion of extra-gastric acid. Thus, if only acid-related symptoms such as heartburn are considered, the reported prevalence in chronic cough is low, whereas if extra-oesophageal symptoms such as hoarseness are considered, reflux appears much more common.

Multiple uncontrolled studies of PPIs report the positive effects in chronic cough and the advice to use PPIs as "anti-reflux" medication in reflux-related cough is enshrined in the guidelines. A systematic review found no conclusive support for the use of PPIs in reflux cough [54]. More recently, two randomised controlled trials confirmed little or no effect of PPIs on chronic cough when compared with placebo (placebo, as is common in the trials of cough, having quite a marked effect over baseline) $[55,56]$. The authors of these trial reports [55,56] concluded that, given the evidence that PPIs may increase the likelihood of aspiration pneumonia [57], PPIs should not be routinely used in the treatment of a reflux cough, but should be reserved for patients exhibiting features of acid-related disease [58] or bronchospasm [59] in addition to cough. The place of pro-motility agents as an alternative to PPIs in the treatment of reflux cough remains controversial.

Question 13

Non-acid gaseous reflux is an important cause of CHS

$\begin{array}{llr}\text { A+ } & \text { Agree strongly } & 5 \\ \text { A } & \text { Agree with minor reservations } & 16 \\ \text { A- } & \text { Agree with major reservations } & 13 \\ \text { D- } & \text { Disagree with major reservations } & 3 \\ \text { D } & \text { Disagree with minor reservations } & 2 \\ \text { D+ } & \text { Disagree strongly } & 4\end{array}$

The majority of our opinion leaders agreed with the statement that non-acid gaseous reflux is an important cause of cough, although most had reservations. The lack of an agreed definition, normal range and "gold standard" diagnostic test for this form of reflux indicates a belief rather than objective scientific evidence supporting these assertions.

Currently, the diagnosis of non-acid reflux relies on the symptom profile reported by the patient. Prandial, post-prandial and positional precipitation of cough, along with extra-oesophageal features such as hoarseness, throat clearing and unusual taste, can be considered as pointers [5]. The lack of confirmatory 
objective diagnostics is a problem. Conventional oesophageal studies detect acid reflux. Oesophageal impedance measurements fail to detect change in the upper oesophagus because of catheter placement. The detection of the pepsin in saliva has a high specificity, but requires frequent sampling [60]. Until reliable and validated methods of detection of non-acid reflux are developed, this will remain a clinical and therefore speculative diagnosis.

Finally, gastro-oesophageal reflux may also trigger cough indirectly through activation of neuronal pathways that link the oesophagus to the airway. The concept of the "oesophago-bronchial reflex" has been supported by studies that have infused acid into the distal oesophagus to cause increased cough frequency [61] and cough reflex sensitivity [62] in patients with chronic cough and associated gastro-oesophageal reflux disease. Oesophageal acid infusion does not change cough reflex sensitivity in healthy volunteers [62]. This oesophago-bronchial reflex seems to be unique to those patients with chronic cough and associated gastro-oesophageal reflux disease. The mechanisms by which the vagal pathways may be altered to allow for the presence of gastrointestinal-airway neuronal interactions is not known, but may be related to mechanisms of central sensitisation and is supported by the observed association of chronic cough with irritable bowel syndrome [63].

\section{Rhinosinusitis/postnasal drip syndrome/upper airway cough syndrome}

\section{Question 14}

Rhinosinusitis is a common cause of cough

$\begin{array}{llr}\text { A+ } & \text { Agree strongly } & 17 \\ \text { A } & \text { Agree with minor reservations } & 15 \\ \text { A- } & \text { Agree with major reservations } & 5 \\ \text { D- } & \text { Disagree with major reservations } & 4 \\ \text { D } & \text { Disagree with minor reservations } & 2 \\ \text { D+ } & \text { Disagree strongly } & 1\end{array}$

The opinion leaders clearly thought that disorders of the upper airway were an important component of chronic cough. Prospective studies performed in the USA [13], Europe [14] and Asia [64] have reported a common association. The American College of Chest Physicians replaced the term "postnasal drip syndrome" with "upper airway cough syndrome", to suggest the possibility that cough could be due not only to the postnasal drip itself, but to irritation or inflammation of upper airway structures that directly stimulate cough receptors [13], although evidence for such activity in humans is sparse. In Japan, a similar entity termed sinobronchial syndrome is reported to be among the most common causes of chronic cough [64].

The concept of a "unified airway" has been proposed, based on epidemiological and physiological data suggesting that the upper and lower airways may be linked through local inflammatory processes $[65,66]$. Consistent with this hypothesis, recent studies of induced cough in humans have demonstrated enhancement of cough reflex sensitivity in the presence of rhinosinusitis. In addition, nasal challenge with menthol is known to diminish cough reflex sensitivity and urge-to-cough sensation in healthy volunteers [67]. Empirical therapy with first-generation antihistamines (with or without a decongestant) has proved to be a successful approach [68], although questions remain as to whether this is due to the amelioration of the underlying disorder or to an intrinsic antitussive effect of these agents [69].

Question 15

Rhinosinusitis/postnasal drip syndrome/upper airway cough syndrome is an integral component of CHS

$\begin{array}{llr}\text { A+ } & \text { Agree strongly } & 3 \\ \text { A } & \text { Agree with minor reservations } & 13 \\ \text { A- } & \text { Agree with major reservations } & 8 \\ \text { D- } & \text { Disagree with major reservations } & 4 \\ \text { D } & \text { Disagree with minor reservations } & 8 \\ \text { D+ } & \text { Disagree strongly } & 7\end{array}$

CHS provides a unifying paradigm whereby a number of conditions that manifest clinically with troublesome cough can be categorised and so managed in an effective manner. From the responses to the questionnaire, whether the causes of cough can be extended to include disease in the upper airway divides opinion.

The very first descriptions of cough associated with the upper airway focused on the term "postnasal drip syndrome" [70], although it is apparent that this anatomically precise clinical description is not uniformly described by patients or indeed recognised by clinicians $[71,72]$. More recently, the term "upper airway 
cough syndrome" has been favoured [73]. Despite sparse evidence from randomised controlled trials, nasal decongestants and first-generation antihistamines have been advocated as first-line therapy [74]. What is not in doubt is that some patients with cough have significant upper airways disease, most typically with a pattern of rhinosinusitis [75]. Effective treatment directed at this local inflammation results in improvement of both cough and cough hypersensitivity [76, 77]. The question as to how disease in the upper airway (largely innervated by the trigeminal nerve) can modulate the cough reflex, the afferent component of which is served by the vagus nerve, is not clear. It is possible that cough is due to mechanical stimulation of the laryngopharyngeal region by mucus, although, as already suggested, a more plausible explanation is that disease is not confined to the upper airway but that inflammation of the entire airway is present [78].

\section{Cough and genetics}

Question 16

Given our current knowledge, genetic studies are only clinically useful in cough associated with neurological syndromes

$\begin{array}{llr}\text { A+ } & \text { Agree strongly } & 7 \\ \text { A } & \text { Agree with minor reservations } & 13 \\ \text { A- } & \text { Agree with major reservations } & 12 \\ \text { D- } & \text { Disagree with major reservations } & 5 \\ \text { D } & \text { Disagree with minor reservations } & 5 \\ \text { D+ } & \text { Disagree strongly } & 1\end{array}$

Most opinion leaders agreed with reservations that genetic studies are only useful in cough associated with neurological conditions. Unlike conditions such as asthma and atopy, where patients frequently report that other family members are affected, chronic cough appears to run in families less often. Caution should be exercised, however, when taking the family history, since relatives may have been given alternative diagnoses such as asthma or bronchiectasis as the cause of their cough. However, a sole genetic basis for chronic cough in most patients would seem unlikely.

A small number of rare heritable conditions have been described in association with chronic cough. Notably, all are neurological conditions. Examples include a variant of autosomal hereditary sensory neuropathy associated with gastro-oesophageal reflux disease and cough described in two Australian families [79], familial Creutzfeldt-Jakob disease associated with dry cough in a single Canadian family [80] and an autosomal dominant cerebellar ataxia in six Portuguese families where the cerebellar signs were preceded by spasmodic cough [81].

The possibility that genetic polymorphisms might be important in the predisposition to develop a chronic cough has not been extensively explored. An insertion/deletion polymorphism in the angiotensinconverting enzyme $(A C E)$ gene, however, may predispose to the development of ACE inhibitor-related cough [82]. A single study has suggested that a polymorphism in the TRPV1 gene might reduce the risk of cough and wheeze in subjects with asthma, although the risk of asthma was not changed [83]. Finally, another study suggested that two polymorphisms in the neurokinin 2 receptor gene are associated with heightened sensitivity to capsaicin in chronic cough patients [84].

The fact that genome-wide association studies have now identified loci influencing lung function [85] is encouraging for its use in identifying loci that might govern the predisposition to CHS.

\section{Cough therapeutics \\ Question 17}

Currently available drugs are largely ineffective in the treatment of CHS

$\begin{array}{llr}\text { A+ } & \text { Agree strongly } & 15 \\ \text { A } & \text { Agree with minor reservations } & 11 \\ \text { A- } & \text { Agree with major reservations } & 10 \\ \text { D- } & \text { Disagree with major reservations } & 5 \\ \text { D } & \text { Disagree with minor reservations } & 1 \\ \text { D+ } & \text { Disagree strongly } & 2\end{array}$

The majority of responders agreed with the statement that currently available drugs are largely ineffective in CHS. Oral morphine, gabapentin and amitriptyline may be considered as being the only currently available drugs acting as direct antitussives [86-88]. The evidence for an effect on cough hypersensitivity is lacking, however. For example, in both the double-blind controlled studies of oral morphine and of gabapentin, there was no positive effect on the capsaicin cough response despite a suppression of either 
cough counts or cough symptoms. A possible explanation is that the capsaicin cough response is not directly related to CHS. However, these agents are generally regarded as having limited clinical utility, as was agreed by $80 \%$ of responders. The lack of a consensus may also be due to the experience of some clinicians who have seen reversible cough in conditions such as asthma. A further confounding feature is the large placebo element in the response to antitussives. The consensus provided by our opinion leaders, that current drugs are not effective, confirms the need for the future development of truly efficacious agents for this condition.

\section{Cough paediatrics}

Question 18

Cough in children is essentially similar to that in adults

$\begin{array}{llr}\text { A+ } & \text { Agree strongly } & 2 \\ \text { A } & \text { Agree with minor reservations } & 4 \\ \text { A- } & \text { Agree with major reservations } & 16 \\ \text { D- } & \text { Disagree with major reservations } & 4 \\ \text { D } & \text { Disagree with minor reservations } & 12 \\ \text { D+ } & \text { Disagree strongly } & 4\end{array}$

The opinion leaders' view of the question, that cough in children is essentially similar to that in adults, is divergent. Although it is hard to explain this diversity of opinion, the fact that relatively few paediatricians were interrogated may have contributed to this result.

During childhood, the respiratory tract and nervous system undergo a series of anatomical and physiological maturation processes that influence the cough reflex. In addition, the immunological response undergoes developmental and memorial processes [89]. The sensitivity of the cough reflex varies with age and sex $[90,91]$. Children are more vulnerable to various environmental factors. Unsurprisingly, the aetiology and management of cough in the child differ from that in adults.

One of the earliest occurrences of cough in the newborn is just at the beginning of a cry. This "cough cry sequence" appears at about 1-2 months and is possibly a protective clearing of the airway of secretions prior to the inspiration of crying [92]. In the first months of life, coughing typifies airway infections such as respiratory syncytial virus (RSV). The pattern of response in RSV-infected infants is characteristic of laryngeal chemoreflex apnoea [93]. Preterm infants infected with RSV often present with apnoea; cough comes later in the course of the infection. Similarly, pertussis infection in preterm infants presents as apnoea with a later onset of the classical "whoop" and cough. Most cases of chronic cough at preschool age are caused by protracted bacterial bronchitis [94], with airways anomalies, mostly tracheobronchomalacia, foreign body aspiration and post-infectious cough, being less common presentations. In contrast to adults, bronchiectasis, asthma, gastro-oesophageal reflux and upper airway cough syndrome appear to be less frequent in this age group [95]. Cough in adolescents is similar to that in adults.

Cough in children should be treated on the basis of aetiology and no evidence supports the use of medication for symptomatic cough relief or an empirical approach based on the big three adult phenotypes [96]. Because of the dissimilarities between cough in children and that in adults and regardless of setting and age, children should be evaluated carefully using child-specific protocols.

\section{Cough in other diseases}

Question 19

CHS is a common feature of a range of pulmonary disorders

$\begin{array}{llr}\text { A+ } & \text { Agree strongly } & 15 \\ \text { A } & \text { Agree with minor reservations } & 16 \\ \text { A- } & \text { Agree with major reservations } & 7 \\ \text { D- } & \text { Disagree with major reservations } & 2 \\ \text { D } & \text { Disagree with minor reservations } & 3 \\ \text { D+ } & \text { Disagree strongly } & 1\end{array}$

Having accepted the clinical utility of the CHS in explaining the respiratory symptoms of patients with chronic cough, the majority of opinion leaders agreed that it may be usefully applied to other respiratory conditions. Afferent neuronal hypersensitivity may therefore represent a common mechanism for the genesis of symptoms in pathologically diverse disorders. The patient with chronic cough may thus represent just the most obvious example (because of its currently obscure aetiology) of where hypersensitivity leads to respiratory morbidity. Other symptoms, such as chest tightness and dyspnoea, 
as well as other conditions, such as chronic bronchitis and laryngeal dysfunction, may be precipitated through overactivity of airway sensory nerves. Indeed, hypersensitivity may be an important component of many diverse pulmonary disorders, such as asthma, COPD, pulmonary fibrosis and pulmonary hypertension. Until specific antagonists of neuronal hypersensitivity in airway C-fibres are developed, the precise role of visceral autonomic sensation in the production of symptoms in respiratory disease remains unclear.

CHS and quality of life

Question 20

The adverse impact of CHS on quality of life is underrecognised by clinicians

$\begin{array}{llr}\text { A+ } & \text { Agree strongly } & 31 \\ \text { A } & \text { Agree with minor reservations } & 9 \\ \text { A- } & \text { Agree with major reservations } & 1 \\ \text { D- } & \text { Disagree with major reservations } & 1 \\ \text { D } & \text { Disagree with minor reservations } & 1 \\ \text { D+ } & \text { Disagree strongly } & 1\end{array}$

The opinion leaders overwhelmingly agreed that the adverse impact of CHS on quality of life is underrecognised by clinicians.

Studies show that chronic cough significantly impairs patients' quality of life. A UK postal survey found that the majority of people reporting cough were distressed, angry, anxious and depressed, and 64\% felt the cough interfered with their social and family life [97, 98]. However, the relationship between health status and cough reflex sensitivity, as defined by inhalational challenge, is weak. This suggests that, similarly to pharmacological effects of drugs on the cough reflex, the adverse effects of chronic cough that determine health status are not directly related to cough reflex hypersensitivity [95, 99].

The physical cough-related adverse symptoms are usually easily apparent to the physician from the clinical history. The psychosocial impact has generally been underrecognised by physicians and is seldom inquired about.

As a relatively new clinical entity, CHS is still poorly identified by most clinicians and patients. Many patients with chronic cough are extremely frustrated by the lack of understanding and the lack of a firm diagnosis provided by healthcare professionals. This is compounded by the tendency to trivialise the impact of cough or to ascribe a psychogenic aetiology because of this poor understanding. For patients, having a diagnosis of CHS and realising that there is a pathophysiological basis for their symptoms is of considerable benefit. Removing the "nothing is wrong with them" response improves psychological well-being and quality of life [97].

\section{Cough engagement}

Question 21

The currently available cough patient support groups are adequate to address patient needs

$\begin{array}{llr}\text { A+ } & \text { Agree strongly } & 1 \\ \text { A } & \text { Agree with minor reservations } & 4 \\ \text { A- } & \text { Agree with major reservations } & 6 \\ \text { D- } & \text { Disagree with major reservations } & 7 \\ \text { D } & \text { Disagree with minor reservations } & 8 \\ \text { D+ } & \text { Disagree strongly } & 18\end{array}$

The majority of opinion leaders strongly disagree that cough patient support groups are adequate to address patient needs. There is a lack of patient-oriented information regarding chronic cough. In an attempt to address this problem, the European Lung Foundation (ELF) team have created a website to increase patient involvement and spread the CHS message. $60 \%$ of patients responding experienced a moderate to severe impairment of quality of life. $81 \%$ reported a limitation of activities they would like to do. $91 \%$ felt fed up or depressed because of their cough [100].

By improving cough patient support groups, many management issues, such as the spread of new information, funding, administration of patient flows, education of healthcare professionals and patients, creating guidelines and collaboration, will be facilitated. 


\section{Discussion}

There was a high degree of agreement among opinion leaders as to the concept that cough hypersensitivity underlies the aetiology of chronic cough in the majority of patients. The CHS was considered as an overarching diagnosis, with different phenotypes associated with distinct presentations in individual patients. While there were differences in the understanding and interpretation of the aetiology and treatment of CHS, it was clearly felt that having a distinct entity to describe the majority of patients was valuable. The use of a single umbrella term has been previously successfully applied in respiratory medicine. COPD is a useful overarching term to describe patients characterised by airflow obstruction but exhibiting different phenotypes such as emphysema and chronic bronchitis. As with CHS, a diagnosis of COPD does not limit further exploration of the different facets of the illness but rather allows a shorthand expression of a single unifying feature (a reduction in forced expiratory volume in $1 \mathrm{~s}$ ). Where CHS differs from COPD is that the feature which would define the syndrome, the hypersensitivity of the afferent airway nerves, is difficult to measure. The inhalation of agents, such as aerosols of capsaicin or complex acids, is insufficiently specific for routine clinical practice. Until such an assessment is available, the characteristic clinical history provides the diagnostic framework.

Within CHS, the classic phenotypes of reflux, asthma and rhinitis were all recognised by our opinion leaders. Eosinophilic disease, variously termed as subtypes of asthma or as forms of eosinophilic bronchitis, was overwhelmingly supported. Recognition of these syndromes presents the most therapeutic opportunity, since treatment directed at T-helper cell type 2 inflammation was considered the optimal strategy. Unfortunately, outside the expert opinion elicited in this survey, these are frequently seen as the only phenotypes causing cough, with much costly and ineffective treatment being prescribed. Whether a monitored therapeutic trial of oral prednisolone should be advocated as a diagnostic test of eosinophilic disease was supported by the majority but with some opinion leaders dissenting strongly. Clearly, further evidence is required for this and other noninvasive measures such as FeNO. The efficacy of current and future treatment directed at eosinophilic inflammation contrasts with the paucity of the therapy in other forms of cough, perhaps explaining the enthusiasm for this diagnostic label.

The place of reflux disease in the aetiology of CHS was found to be more problematic. There was evident disagreement between the opinion leaders as to the relative role of acid and non-acid reflux and the therapeutic effect of acid suppressant therapy. The Task Force literature review did not support the current guidelines position that a trial of acid suppressive therapy should be used in routine management, particularly in those without peptic symptoms. The use of PPIs was only advocated in those with significant heartburn. Because of the lack of further objective criteria, it was concluded that, while non-acid reflux was an attractive aetiological agent in the current state of knowledge, it was considered "not proven".

Rhinitis was clearly identified as an aetiological factor in chronic cough, but how disease in an anatomical area not innervated by the vagus produced what was considered to be a vagally mediated sensation was unclear. This confusion of association and aetiology of cough in rhinitis illustrates the division of opinion between North America and Europe as to the nature of cough. Our opinion leaders were predominantly drawn from the membership of the ERS and supported the association of rhinitis with cough but were split as to the aetiological link. Using the umbrella term of the CHS to include patients with prominent rhinitic features does not infer the origin of the disease. The use of the term upper airway cough syndrome by the American College of Chest Physicians does infer a separate entity contrasting with the paradigm of the "unified airway" hypothesis. The presence of a laryngeal hypersensitivity state as part of CHS may underlie many of the symptoms associated with rhinitis, including cough.

The major impact of chronic cough on quality of life and the high degree of associated morbidity was recognised by our opinion leaders. There was also recognition that the needs of the patient with chronic cough were being inadequately appreciated. This opinion was supported by the recent survey conducted by the ELF that found that $88 \%$ of respondents said they would like more information on cough to be available. The most requested information was on chronic cough treatments, better information on what chronic cough is, and on the causes of chronic cough. They also wanted better treatment and support from doctors, location and access to specialist cough centres, and treatments specifically for chronic cough. While the opinion leaders have clearly accepted the concept of CHS and understand the impact of this condition on the patient's lives, this has not been translated into the distribution of resources to support patients.

There are a number of limitations inherent in a survey of this kind. The topics covered are dependent on the adequacy of the literature survey conducted, but more particularly on the interpretation of the findings revealed. It is entirely possible that highly significant questions remain unasked. For example, the issue of sex was not considered important because of the paucity of the published literature, whereas the most recent findings suggest that there is a highly significant excess of females in the population presenting with chronic cough [101]. There are several limitations of questionnaire development. In the classic "Delphic" method, 
further refinement of questions would have been undertaken with opinion leaders. We considered this inappropriate given the timescale that the Task Force was operating under. It could be argued that it was also unnecessary, since the purpose of this survey was to elicit attitudinal information on a new concept rather than to establish current clinical practice in a recognised area. Clearly this is a small sample size, but there was a surprisingly unanimity of opinion in the majority of questions, which also reflect the Task Force literature review. The only major disparities in the consensus were those in the role of rhinitis as an aetiological agent in chronic cough and in the efficacy of PPIs in the treatment of reflux-associated cough. Both of these issues reflected genuine disparity of opinion within the literature rather than our relatively small sample size. It could be argued that our opinion leaders do not reflect the true expert opinion of those knowledgeable about chronic cough. However, the panel was selected from individuals with considerable clinical and research experience in relevant respiratory specialties and representing global practice. As an ERS Task Force, respiratory opinion was canvassed and it is acknowledged that other clinical specialties treating patients with CHS may have different opinions. Future efforts may need to be directed to other healthcare professionals dealing with patients suffering from chronic cough. However, provided the limitations of this exercise are recognised, we believe that this survey has revealed a high degree of acceptance of CHS as a clinical entity, valuable in the diagnosis of, management of and communication with the patient with chronic cough.

The Task Force recommends that further efforts be made to research, at both basic and clinical levels, the aetiology and diagnostic pathways for cough and that further consideration should be given now to supporting management and therapeutic initiatives in this area, factors which were clearly agreed by those key opinion leaders participating in the study.

\section{References}

1 Morice AH. The cough hypersensitivity syndrome: a novel paradigm for understanding cough. Lung 2010; 188: Suppl. 1, S87-S90.

2 Chung KF. Chronic "cough hypersensitivity syndrome": a more precise label for chronic cough. Pulm Pharmacol Ther 2011; 24: 267-271.

Millqvist E. The airway sensory hyperreactivity syndrome. Pulm Pharmacol Ther 2011; 24: 263-266.

4 Pacheco-Galvan A, Hart SP, Morice AH. Relationship between gastro-oesophageal reflux and airway diseases: the airway reflux paradigm. Arch Bronconeumol 2011; 47: 195-203.

5 Morice AH, Faruqi S, Wright CE, et al. Cough hypersensitivity syndrome: a distinct clinical entity. Lung 2011; 189: 73-79.

6 Johansson A, Millqvist E, Nordin S, et al. Relationship between self-reported odor intolerance and sensitivity to inhaled capsaicin: proposed definition of airway sensory hyperreactivity and estimation of its prevalence. Chest 2006; 129: 1623-1628.

7 Chung KF, McGarvey LP, Mazzone SB. Chronic cough as a neuropathic disorder. Lancet Respir Med 2013; 1 : 414-422.

8 Pacheco A, Cobeta I, Wagner C. Refractory chronic cough: new perspectives in diagnosis and treatment. Arch Bronconeumol 2013; 49: 151-157.

9 Abdullah H, Heaney LG, Cosby SL, et al. Rhinovirus upregulates transient receptor potential channels in a human neuronal cell line: implications for respiratory virus-induced cough reflex sensitivity. Thorax 2014; 69: 46-54.

10 Groneberg DA, Niimi A, Dinh QT, et al. Increased expression of transient receptor potential vanilloid-1 in airway nerves of chronic cough. Am J Respir Crit Care Med 2004; 170: 1276-1280.

11 Irwin RS, Curley FJ, French CL. Chronic cough. The spectrum and frequency of causes, key components of the diagnostic evaluation, and outcome of specific therapy. Am Rev Respir Dis 1990; 141: 640-647.

12 Palombini BC, Villanova CA, Araujo E, et al. A pathogenic triad in chronic cough: asthma, postnasal drip syndrome, and gastroesophageal reflux disease. Chest 1999; 116: 279-284.

13 Irwin RS, Baumann MH, Bolser DC, et al. Diagnosis and management of cough executive summary: ACCP evidence-based clinical practice guidelines. Chest 2006; 129: Suppl. 1, 1S-23S.

14 Morice AH, Fontana GA, Sovijarvi AR, et al. The diagnosis and management of chronic cough. Eur Respir J 2004; 24: 481-492.

15 Morice AH, McGarvey LP, Dicpinigaitis PV. Cough hypersensitivity syndrome is an important clinical concept: a pro/con debate. Lung 2012; 190: 3-9.

16 Crapo RO, Casaburi R, Coates AL, et al. Guidelines for methacholine and exercise challenge testing - 1999. This official statement of the American Thoracic Society was adopted by the ATS Board of Directors, July 1999. Am J Respir Crit Care Med 2000; 161: 309-329.

17 Vertigan AE, Gibson PG. Chronic refractory cough as a sensory neuropathy: evidence from a reinterpretation of cough triggers. J Voice 2011; 25: 596-601.

18 Canning BJ. Functional implications of the multiple afferent pathways regulating cough. Pulm Pharmacol Ther 2011; 24: 295-299.

19 Dicpinigaitis PV. Review: Effect of drugs on human cough reflex sensitivity to inhaled capsaicin. Cough 2012; 8: 10.

20 Birrell MA, Belvisi MG, Grace M, et al. TRPA1 agonists evoke coughing in guinea pig and human volunteers. Am J Respir Crit Care Med 2009; 180: 1042-1047.

21 Riccio MM, Myers AC, Undem BJ. Immunomodulation of afferent neurons in guinea-pig isolated airway. J Physiol 1996; 491: 499-509.

22 Nasra J, Belvisi MG. Modulation of sensory nerve function and the cough reflex: understanding disease pathogenesis. Pharmacol Ther 2009; 124: 354-375. 
Neumann S, Doubell TP, Leslie T, et al. Inflammatory pain hypersensitivity mediated by phenotypic switch in myelinated primary sensory neurons. Nature 1996; 384: 360-364.

24 Lieu TM, Myers AC, Meeker S, et al. TRPV1 induction in airway vagal low-threshold mechanosensory neurons by allergen challenge and neurotrophic factors. Am J Physiol Lung Cell Mol Physiol 2012; 302: L941-L948.

25 Zhang G, Lin RL, Wiggers M, et al. Altered expression of TRPV1 and sensitivity to capsaicin in pulmonary myelinated afferents following chronic airway inflammation in the rat. J Physiol 2008; 586: 5771-5786.

26 Prudon B, Birring SS, Vara DD, et al. Cough and glottic-stop reflex sensitivity in health and disease. Chest 2005; 127: 550-557.

27 Morice AH, Fontana GA, Belvisi MG, et al. ERS guidelines on the assessment of cough. Eur Respir J 2007; 29: 1256-1276.

28 Hilton EC, Baverel PG, Woodcock A, et al. Pharmacodynamic modeling of cough responses to capsaicin inhalation calls into question the utility of the C5 end point. J Allergy Clin Immunol 2013; 132: 847-855.

29 Dicpinigaitis PV. Short- and long-term reproducibility of capsaicin cough challenge testing. Pulm Pharmacol Ther 2003; 16: 61-65.

30 Hoffmeyer F, Sucker K, Rosenkranz N, et al. Reproducibility of sensitivity to capsaicin assessed by single breath inhalation methodology. Adv Exp Med Biol 2013; 755: 71-78.

31 Nieto L, de Diego A, Perpina M, et al. Cough reflex testing with inhaled capsaicin in the study of chronic cough. Respir Med 2003; 97: 393-400.

32 Ekstrand Y, Ternesten-Hasseus E, Arvidsson M, et al. Sensitivity to environmental irritants and capsaicin cough reaction in patients with a positive methacholine provocation test before and after treatment with inhaled corticosteroids. J Asthma 2011; 48: 482-489.

33 Wong $\mathrm{CH}$, Morice AH. Cough threshold in patients with chronic obstructive pulmonary disease. Thorax 1999; 54: $62-64$.

34 Terada K, Muro S, Ohara T, et al. Cough-reflex sensitivity to inhaled capsaicin in COPD associated with increased exacerbation frequency. Respirology 2009; 14: 1151-1155.

Joo JH, Park SJ, Park SW, et al. Clinical features of eosinophilic bronchitis. Korean J Intern Med 2002; 17 : $31-37$. Pavord ID, Chung KF. Management of chronic cough. Lancet 2008; 371: 1375-1384.

Chung KF, Hew M, Score J, et al. Cough and hypereosinophilia due to FIP1L1-PDGFRA fusion gene with tyrosine kinase activity. Eur Respir J 2006; 27: 230-232.

38 Haldar P, Brightling CE, Hargadon B, et al. Mepolizumab and exacerbations of refractory eosinophilic asthma. N Engl J Med 2009; 360: 973-984.

39 Pacheco A, Faro V, Cobeta I, et al. Gastro-oesophageal reflux, eosinophilic airway inflammation and chronic cough. Respirology 2011; 16: 994-999.

40 Berry MA, Hargadon B, McKenna S, et al. Observational study of the natural history of eosinophilic bronchitis. Clin Exp Allergy 2005; 35: 598-601.

41 Corrao WM, Braman SS, Irwin RS. Chronic cough as the sole presenting manifestation of bronchial asthma. $N$ Engl J Med 1979; 300: 633-637.

42 Osman LM, McKenzie L, Cairns J, et al. Patient weighting of importance of asthma symptoms. Thorax 2001; 56: $138-142$.

43 Niimi A. Cough and asthma. Curr Respir Med Rev 2011; 7: 47-54.

44 Brightling CE, Ward R, Goh KL, et al. Eosinophilic bronchitis is an important cause of chronic cough. Am J Respir Crit Care Med 1999; 160: 406-410.

45 Brightling CE, Ward R, Woltmann G, et al. Induced sputum inflammatory mediator concentrations in eosinophilic bronchitis and asthma. Am J Respir Crit Care Med 2000; 162: 878-882.

46 Brightling CE, Ward R, Wardlaw AJ, et al. Airway inflammation, airway responsiveness and cough before and after inhaled budesonide in patients with eosinophilic bronchitis. Eur Respir J 2000; 15: 682-686.

47 Gibson PG, Hargreave FE, Girgis-Gabardo A, et al. Chronic cough with eosinophilic bronchitis: examination for variable airflow obstruction and response to corticosteroid. Clin Exp Allergy 1995; 25: 127-132.

48 Hunter CJ, Brightling CE, Woltmann G, et al. A comparison of the validity of different diagnostic tests in adults with asthma. Chest 2002; 121: 1051-1057.

49 Chatkin JM, Ansarin K, Silkoff PE, et al. Exhaled nitric oxide as a noninvasive assessment of chronic cough. Am J Respir Crit Care Med 1999; 159: 1810-1813.

50 Smith AD, Cowan JO, Filsell S, et al. Diagnosing asthma: comparisons between exhaled nitric oxide measurements and conventional tests. Am J Respir Crit Care Med 2004; 169: 473-478.

51 Wechsler ME. Pulmonary eosinophilic syndromes. Immunol Allergy Clin North Am 2007; 27: 477-492.

52 Shim CS, Williams MH Jr. Cough and wheezing from beclomethasone dipropionate aerosol are absent after triamcinolone acetonide. Ann Intern Med 1987; 106: 700-703.

53 Faruqi S, Morice AH. Epidemiology and pathophysiology of chronic cough. Curr Respir Med Rev 2011; 7: 5-9.

54 Chang AB, Lasserson TJ, Kiljander TO, et al. Systematic review and meta-analysis of randomised controlled trials of gastro-oesophageal reflux interventions for chronic cough associated with gastro-oesophageal reflux. BMJ 2006; 332: 11-17.

55 Faruqi S, Molyneux ID, Fathi H, et al. Chronic cough and esomeprazole: a double-blind placebo-controlled parallel study. Respirology 2011; 16: 1150-1156.

56 Shaheen NJ, Crockett SD, Bright SD, et al. Randomised clinical trial: high-dose acid suppression for chronic cough - a double-blind, placebo-controlled study. Aliment Pharmacol Ther 2011; 33: 225-234.

57 Herzig SJ, Howell MD, Ngo LH, et al. Acid-suppressive medication use and the risk for hospital-acquired pneumonia. JAMA 2009; 301: 2120-2128.

58 Kahrilas PJ, Howden CW, Hughes N, et al. Response of chronic cough to acid-suppressive therapy in patients with gastroesophageal reflux disease. Chest 2013; 143: 605-612.

59 Dal Negro RW, Tognella S, Micheletto C, et al. A MCh test pre-post esophageal acidification in detecting GERrelated asthma. J Asthma 2009; 46: 351-355.

60 Strugala V, Dettmar PW, Morice AH. Detection of pepsin in sputum and exhaled breath condensate: could it be a useful marker for reflux-related respiratory disease? Gastroenterology 2009; 136: Suppl. 1, S1895. 
61 Ing AJ, Ngu MC, Breslin AB. Pathogenesis of chronic persistent cough associated with gastroesophageal reflux. Am J Respir Crit Care Med 1994; 149: 160-167.

62 Javorkova N, Varechova S, Pecova R, et al. Acidification of the oesophagus acutely increases the cough sensitivity in patients with gastro-oesophageal reflux and chronic cough. Neurogastroenterol Motil 2008; 20: 119-124.

63 Ford AC, Forman D, Moayyedi P, et al. Cough in the community: a cross sectional survey and the relationship to gastrointestinal symptoms. Thorax 2006; 61: 975-979.

64 Kohno S, Ishida T, Uchida Y, et al. The Japanese Respiratory Society guidelines for management of cough. Respirology 2006; 11: Suppl. 4, S135-S186.

65 Krouse JH, Altman KW. Rhinogenic laryngitis, cough, and the unified airway. Otolaryngol Clin North Am 2010; 43: $111-121$.

66 Braunstahl GJ, Overbeek SE, Fokkens WJ, et al. Segmental bronchoprovocation in allergic rhinitis patients affects mast cell and basophil numbers in nasal and bronchial mucosa. Am J Respir Crit Care Med 2001; 164: 858-865.

67 Buday T, Brozmanova M, Biringerova Z, et al. Modulation of cough response by sensory inputs from the nose role of trigeminal TRPA1 versus TRPM8 channels. Cough 2012; 8: 11.

68 Pratter MR, Bartter T, Akers S, et al. An algorithmic approach to chronic cough. Ann Intern Med 1993; 119: 977-983.

69 Dicpinigaitis PV. Cough: an unmet clinical need. Br J Pharmacol 2011; 163: 116-124.

70 Irwin RS, Corrao WM, Pratter MR. Chronic persistent cough in the adult: the spectrum and frequency of causes and successful outcome of specific therapy. Am Rev Respir Dis 1981; 123: 413-417.

71 Morice AH. Post-nasal drip syndrome - a symptom to be sniffed at? Pulm Pharmacol Ther 2004; 17: 343-345.

72 O'Hara J, Jones NS. "Post-nasal drip syndrome": most patients with purulent nasal secretions do not complain of chronic cough. Rhinology 2006; 44: 270-273.

73 Pratter MR. Chronic upper airway cough syndrome secondary to rhinosinus diseases (previously referred to as postnasal drip syndrome): ACCP evidence-based clinical practice guidelines. Chest 2006; 129: Suppl. 1, 63S-71S.

74 Irwin RS, Curley FJ, French CL. Chronic cough. The spectrum and frequency of causes, key components of the diagnostic evaluation, and outcome of specific therapy. Am Rev Respir Dis 1990; 141: 640-647.

75 McGarvey LP, Heaney LG, Lawson JT, et al. Evaluation and outcome of patients with chronic non-productive cough using a comprehensive diagnostic protocol. Thorax 1998; 53: 738-743.

76 Macedo P, Saleh H, Torrego A, et al. Postnasal drip and chronic cough: an open interventional study. Respir Med 2009; 103: 1700-1705.

77 O'Hara J, Jones NS. The aetiology of chronic cough: a review of current theories for the otorhinolaryngologist. J Laryngol Otol 2005; 119: 507-514.

78 Plevkova J, Kollarik M, Poliacek I, et al. The role of trigeminal nasal TRPM8-expressing afferent neurons in the antitussive effects of menthol. J Appl Physiol 2013; 115: 268-274.

79 Spring PJ, Kok C, Nicholson GA, et al. Autosomal dominant hereditary sensory neuropathy with chronic cough and gastro-oesophageal reflux: clinical features in two families linked to chromosome 3p22-p24. Brain 2005; 128: $2797-2810$.

80 Larue S, Verreault S, Gould P, et al. A case of familial Creutzfeldt-Jakob disease presenting with dry cough. Can J Neurol Sci 2006; 33: 243-245.

81 Coutinho P, Cruz VT, Tuna A, et al. Cerebellar ataxia with spasmodic cough: a new form of dominant ataxia. Arch Neurol 2006; 63: 553-555.

$82 \mathrm{Li}$ YF, Zhu XM, Liu F, et al. Angiotensin-converting enzyme (ACE) gene insertion/deletion polymorphism and ACE inhibitor-related cough: a meta-analysis. PLoS One 2012; 7: e37396.

83 Cantero-Recasens G, Gonzalez JR, Fandos C, et al. Loss of function of transient receptor potential vanilloid 1 (TRPV1) genetic variant is associated with lower risk of active childhood asthma. J Biol Chem 2010; 285: 27532-27535.

84 Park HK, Oh SY, Kim TB, et al. Association of genetic variations in neurokinin-2 receptor with enhanced cough sensitivity to capsaicin in chronic cough. Thorax 2006; 61: 1070-1075.

85 Wilk JB, Shrine NR, Loehr LR, et al. Genome-wide association studies identify CHRNA5/3 and HTR4 in the development of airflow obstruction. Am J Respir Crit Care Med 2012; 186: 622-632.

86 Morice AH, Menon MS, Mulrennan SA, et al. Opiate therapy in chronic cough. Am J Respir Crit Care Med 2007; 175: 312-315.

87 Ryan NM, Birring SS, Gibson PG. Gabapentin for refractory chronic cough: a randomised, double-blind, placebocontrolled trial. Lancet 2012; 380: 1583-1589.

88 Jeyakumar A, Brickman TM, Haben M. Effectiveness of amitriptyline versus cough suppressants in the treatment of chronic cough resulting from postviral vagal neuropathy. Laryngoscope 2006; 116: 2108-2112.

89 Chang AB, Widdicombe JG. Cough throughout life: children, adults and the senile. Pulm Pharmacol Ther 2007; 20: 371-382.

90 Chang AB, Gibson PG, Willis C, et al. Do sex and atopy influence cough outcome measurements in children? Chest 2011; 140: 324-330.

91 Varechova S, Plevkova J, Hanacek J, et al. Role of gender and pubertal stage on cough sensitivity in childhood and adolescence. J Physiol Pharmacol 2008; 59: Suppl. 6, 719-726.

92 Thach BT. Maturation of cough and other reflexes that protect the fetal and neonatal airway. Pulm Pharmacol Ther 2007; 20: 365-370.

93 Pickens DL, Schefft GL, Storch GA, et al. Characterization of prolonged apneic episodes associated with respiratory syncytial virus infection. Pediatr Pulmonol 1989; 6: 195-201.

94 Marchant JM, Masters IB, Taylor SM, et al. Evaluation and outcome of young children with chronic cough. Chest 2006; 129: 1132-1141

95 Kantar A, Bernardini R, Paravati F, et al. Chronic cough in preschool children. Early Hum Dev 2013; 89: Suppl. 3, S19-S24.

96 Chang AB. Cough: are children really different to adults? Cough 2005; 1: 7.

97 Everett CF, Kastelik JA, Thompson RH, et al. Chronic persistent cough in the community: a questionnaire survey. Cough 2007; 3: 5. 
98 Marchant JM, Newcombe PA, Juniper EF, et al. What is the burden of chronic cough for families? Chest 2008; 134: 303-309.

99 Birring SS, Matos S, Patel RB, et al. Cough frequency, cough sensitivity and health status in patients with chronic cough. Respir Med 2006; 100: 1105-1109.

100 Chamberlain S, Masefield S, Powell P, et al. The impact of chronic cough: a European perspective. Eur Respir J 2013; 42: Suppl. 57, 5037.

101 Morice AH, Jakes AD, Faruqi S, et al. A worldwide survey of chronic cough: a manifestation of enhanced somatosensory response. Eur Respir J 2014; 44: 1149-1155. 